American Journal of Applied Sciences 9 (8): 1203-1213, 2012

ISSN 1546-9239

(C) 2012 Science Publications

\title{
Coreless Winter Characteristics Observed with Global Positioning System Receivers over Antarctic and Arctic Regions
}

\author{
${ }^{1}$ Wayan Suparta, ${ }^{1}$ Faizatul Noor Abu Bakar and ${ }^{1,2}$ Mardina Abdullah \\ ${ }^{1}$ Institute of Space Science (ANGKASA), \\ ${ }^{2}$ Department of Electrical, Electronic and System Engineering, \\ Faculty of Engineering and Built Environment, \\ Universiti Kebangsaan Malaysia, 43600 Bangi, Selangor, Malaysia
}

\begin{abstract}
Problem statement: The most recent warming trends occurred during the winter in Polar Regions had been attracted many researchers to study its impacts, which might affect the sensitivity of climate prediction in both regions, as well as on a global basis. Approach: The aims of this study were to observe the characteristics of coreless winter events using the GPS meteorology such as the Zenith Tropospheric Delay (ZTD), Precipitable Water Vapor (PWV), the surface meteorology and the solar radiation measurements. The periods of observations were within two years which from January 2008 to December 2009 for Antarctic and from July 2008 to June 2010 for the Arctic. Results: The occurrence of coreless winter had clearly detected in June and January for Antarctic and Arctic, respectively. During the winter period, PWV and ZTD, temperature and relative humidity variations in both regions demonstrate a significant unusual warming peak than with the surface pressure. During this event, the increasing of $1{ }^{\circ} \mathrm{C}$ of temperature showed that the PWV in Arctic was observed twice larger compared to the Antarctic. Conclusion: The increased PWV during winter suggest that the coreless winters characteristic is signified when advection between the warm or cold air masses over the region tend to increase the formation of cyclonic activity that causes increasing in surface temperature.
\end{abstract}

Key words: GPS PWV, coreless winter, meteorology, antarctic, arctic

\section{INTRODUCTION}

The Antarctic-Arctic regions (bipolar) are increasingly recognized as the spots which are strongly influenced by the world climate system. Because of bipolar being in the forefronts of climate change issues and a sensitive indicator of global-scale climate change, the proper characterization of the polar atmosphere is essential to improve our understanding of the coupling mechanisms between bipolar and global climates and between the atmospheric, land and oceanic components of the climate system. Accordingly, atmospheric water vapor is particularly important because of their capability to regulate the polar energy balances. For example, small changes of atmospheric water vapor have a much larger impacts on the greenhouse effect and thereby heat the Earth's surface that causes a warming. As it can be seen, a part of both regions in recent years had shown most rapid rates of the warming impact. In the Arctic, the significant warming commence during the 20th century with a magnitude of air temperatures over extensive land areas was expected to increase by up to $5^{\circ} \mathrm{C}$ (Anisimov et al., 2007). The attributions of recent changes are from the natural variability and anthropogenic forcing, which concludes a substantial proportion of the recent variability and manifestation of greenhouse gas induced by human (Serreze and Francis, 2006). The most recent (1980 to present) warming of the Arctic is strongest about $1{ }^{\circ} \mathrm{C} /$ decade in winter and spring (McBean, 2005), while in the Antarctic region, there has been a marked most rapidly warming trend was in the Antarctic Peninsula over the past several decades (Turner et al., 2007). The Antarctic Peninsula stations show a consistent regional rate of warming that is more than twice the average for other Antarctic stations. King and Harangozo (1998) suggest that this warming is associated with an increase in the northerly component of the atmospheric circulation over the Peninsula and perhaps changes in the sea-ice extent.

The significant warmed trends during winter in the Antarctic and Arctic regions have been attracted many researchers to study about the physical mechanism that contributed to the event. The warmer temperature Environment Building, Universiti Kebangsaan Malaysia, 43600 Bangi, Selangor, Malaysia Tel: +603 89214729 Fax: +60389216856 
during winter in the interior of Antarctica was widely accepted, as the 'coreless' or 'kernlose' winter as introduced by Wexler (1958) and Bromwich and Stearns (1993). This phenomenon refers to the winters without cold core, however the temperature trend increase for a few months and leads to a maximum in early winter after a significant drop in autumn season. Several authors (Carroll, 1982; Stone and Kahl, 1991) studied that the increasing of temperature during austral winter was not monotonic and strong sudden warming episodes has been occurred. More studies on temperature behavior during winter in Antarctica, for example, Connolley and Cattle (1994) use pressure and temperature fields to improve the performance of the UKMO Unified Model and found the coreless feature was present in their model, although cloud covers appear to be a problem to their accuracy. Styszynska (2004) examined the relationship between the air temperature at the Arctowski station on the South Shetlands, with the sea ice extent and Sea Surface Temperature (SST) in the Bellingshausen Sea and the event of coreless winter was identified pronounced in July. In addition, Hudson and Brandt (2005) studied about the relationship between the inversion temperature profile with radiosonde data over the Antarctic Plateau at different scales, with winds and downward long-wave radiation and found that the distributions of temperature inversions are more common and stronger in winter than in summer. Because winters are severe in Antarctica and the period of coreless winter was remarkably different for each region, their origin and causes are important before it strikes. Moreover, the physical process of coreless during the winter has still poorly understood. In this study, we propose water vapor monitoring with groundbased Global Positioning System (GPS) technique to characterize the coreless winter behavior.

The GPS is an accurate and powerful technique to retrieve the Precipitable Water Vapor (PWV) in all weather conditions from single station observations and/or in ground-based network with fine temporal and spatial resolution. This technique was first described by Bevis et al. (1992) and Duan et al. (1996), which GPS satellite radio signals were slowed caused by originates of both the ionosphere and the neutral atmosphere. To determine the PWV from GPS signal delays, the process is accomplished by separating the errors introduced into the calculation by system-related and geometric factors caused the passage of the GPS signal through the atmosphere (Gutman et al., 1994). As the ionosphere delay is frequency dependent, it can be corrected by using dual-frequency GPS receivers and the remaining delay, neutral delay, is depending on its constituents in the lower atmosphere. The neutral delay, so-called the total tropospheric delay consists of a 'hydrostatic' delay and a 'wet' delay. The hydrostatic delay containing about $90 \%$ of dry gases in the troposphere and the non-dipole component of water vapor refractivity, while the wet delay is associated with the distribution of water vapor overlying from a GPS receiver to the top of the atmosphere (Haan, 2008). On the other hand, the total tropospheric delay is the sum of the hydrostatic delay and wet delay. The PWV can be estimated from the Zenith Wet Delay (ZWD) after the GPS signals mapped to satellite view. Section of materials and methods gives a brief explanation of the PWV determination. Several studies have demonstrated that GPS PWV has been compared with radiosonde or microwave radiometers and found the accuracy consistently in levels of 1 2 mm (Rocken et al., 1997; Elgered et al., 1997). More presently, it can be used to improve mesoscale NWP model (Kuo et al., 2000) and for climate monitoring (Gradinasky et al., 2002). The GPS PWV also can be used as a proxy of upper-lower atmospheric coupling studies as proposed by Suparta et al. (2008). In this study, the impact of GPS PWV is employed to study the response of coreless winter behavior. In the analysis, the similarities or differences of coreless winter in the Antarctic and Arctic regions are observed. The location of study for this study is focused at two stations for each region, which Scott Base (SBA) and Syowa (SYOG) for Antarctic while in the Arctic are Thule (THU2) and Reykjavik (REYK). For the analysis, PWV and the surface meteorology data over the period from January 2008 to December 2009 for Antarctic and from July 2008 to June 2010 for the Arctic are processed. The measurement results are then analyzed on a monthly basis to give a clear response of surface parameters on coreless winter events.

\section{MATERIALS AND METHODS}

Location: Figure 1 depicts the location of fixed GPS sites at both regions. SBA in the right of the figure is located at Pram Point which 1,353 km away from the South Pole, at the near tip of Hut Point Peninsula on Ross Island region. The station is managed by the New Zealand Antarctic Institute of Antarctica New Zealand (ANZ) and at $3 \mathrm{~km}$ away from the closest neighbor to Scott Base is the American base, McMurdo station (MCM) situated at Discovery Point. Meanwhile, SYOG located on the Ongul Island in Lützow-Holm bay, about $4 \mathrm{~km}$ west from the coast of East Antarctica, is also one permanent station managed by the National Institute of Polar Research (NIPR), Japan. 


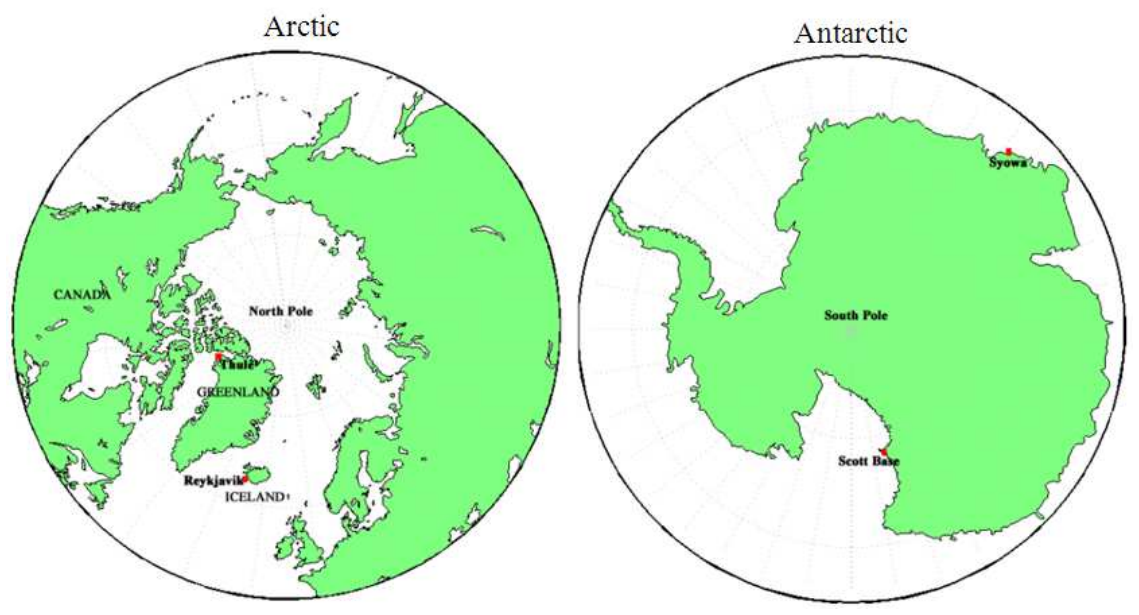

Fig. 1: Location of stations study of bipolar region

Table 1: The geographical coordinates and instrument setup of GPS receivers for both regions

\begin{tabular}{llllll}
\hline $\begin{array}{l}\text { Station } \\
\text { (Country managed) }\end{array}$ & $\begin{array}{l}\text { Latitude } \\
(\mathrm{Deg})\end{array}$ & $\begin{array}{l}\text { Longitude } \\
(\mathrm{Deg})\end{array}$ & $\begin{array}{l}\text { Height } \\
(\mathrm{m})\end{array}$ & $\begin{array}{l}\text { Types of GPS receiver } \\
\text { and year installed }\end{array}$ & $\begin{array}{l}\text { Cut-off elevation } \\
\text { angle (Deg) }\end{array}$ \\
\hline SBA (New Zealand) & $77.85^{\circ} \mathrm{S}$ & $166.76^{\circ} \mathrm{W}$ & 15.85 & Trimble TS5700 (2002) & 13 \\
SYOG (Japan) & $69.00^{\circ} \mathrm{S}$ & $39.58^{\circ} \mathrm{W}$ & 50.09 & Trimble NETRS (2007) & 10 \\
THU2 (United State) & $76.32^{\circ} \mathrm{N}$ & $68.49^{\circ} \mathrm{E}$ & 36.10 & JPS LEGACY (2008) & 5 \\
REYK (Iceland) & $64.08^{\circ} \mathrm{N}$ & $21.57^{\circ} \mathrm{E}$ & 93.10 & TPS E_GGD (2008) & 0 \\
\hline
\end{tabular}

On the left panel of Fig. 1 presents the REYK and THU2 stations in the Arctic region. REYK is located in Southwestern in Iceland, on the southern shore of Faxaflói Bay. For the last station, THU2 is the US Air Force's northernmost base, located 1,118 km north of the Arctic Circle and 1,524 km from the North Pole on the northwest side of the island of Greenland.

Data sets: For this study, the observations employed based on two major data sets that are GPS data and the surface meteorological data. The main base of measurement systems for this study is at SBA, Antarctica. The system employed at SBA consists of a GPS receiving system and a ground meteorological system. The GPS receiver was installed in November 2002 under the Malaysian Antarctic Research Program (MARP) and was maintained by ANZ. At this station, GPS data are collected continuously using a Trimble GPS receiver with a Zephyr Geodetic antenna. The GPS receiver was set to track GPS signals at one second sampling rate and the cut-off elevation angles was set to $13^{\circ}$ to eliminate possible multipath effects in the GPS data. The GPS receiver uses the Trimble TS5700 produced three sets of data in a Trimble binary format (*.dat, *.ion, *.eph).

The GPS data other than SBA obtained from the International GNSS Service (IGS) at the SOPAC homepage (http://sopac.ucsd.edu). Table 1 gives the instrument setup of GPS receivers and geographical coordinates for four stations in both regions. The GPS data at SOPAC were recorded at 30 s intervals and supplied as RINEX (Receiver Independent Exchange Format) files, which observation and navigation are in the format $(* . * \mathrm{~d}, * . * \mathrm{n})$, respectively. All observation files are provided in a Hanataka format (d-file compression) to reduce the storage size of the RINEX file stored in the database. All the GPS data were sampled in $30 \mathrm{Sec}$.

In this study, the surface meteorological data as one input for PWV calculation consists of surface pressure (in mbar), temperature (in ${ }^{\circ} \mathrm{C}$ ) and relative humidity (in percent). The surface meteorological data at SBA maintained by the National Institute of Water and Atmospheric Research Ltd., New Zealand (NIWA) and ANZ. The GPS system was housed at the Hatherton Geosciences Lab. Details of measurement systems at SBA for this study has been reported by Suparta et al. (2008). In order to support the analysis at the SBA, the surface meteorological data for SYOG is obtained from the British Antarctic Survey (BAS), while THU2 and REYK are obtained also from the SOPAC database that stored in a format $(*$ * $* m)$. The sampling periodicity for all surface meteorological data from SBA, SYOG, REYK and THU2 are $10 \mathrm{~min}, 3 \mathrm{~h}, 15$ and $5 \mathrm{~min}$, respectively. 
To identify the clarity of the polar climate seasonal variability, solar radiation data measured in both regions are employed. The global solar radiation data at SBA and Neumayer (NEUM) $\left(70^{\circ} 39^{\prime} \mathrm{S}, 8^{\circ} 15^{\prime} \mathrm{W}\right)$ are representing for Antarctic while solar data at REYK are signifying for the Arctic. However, Sodankyla (SODA) from Finland at $67^{\circ} 22^{\prime} \mathrm{N}, 26^{\circ} 37^{\prime} \mathrm{E}$ and Kiruna (KIRU), Sweden at $67^{\circ} 50^{\prime} \mathrm{N}, 20^{\circ} 13^{\prime} \mathrm{E}$ are used to compare with solar radiation in REYK. Solar radiation data at SBA and NEUM were obtained from NIWA and the Alfred Wegener Institute (AWI) webpage at http://www.awi.de/en. Solar data for the Arctic station were obtained from the World Radiation Data Centre web page (WRDC).

Data processing: The PWV total is determined from both GPS and the surface meteorological data. To convert GPS observation data as available in Hatanaka format into a RINEX file, it requires special software that can be obtained from ftp://terras.gsi.go.jp/software/RNXCMP. On the other hand, the Trimble.dat files were converted into RINEX format $\left(*^{*} *_{\mathrm{O}}\right.$ and $\left.*^{*} \mathrm{n}\right)$ using the Translate/Edit/Quality/Check (TEQC) routine developed by UNAVCO. After all RINEX files available, the TEQC was used to rearrange the data into separate individual data files (C1, L1, L2 and P2) for ease processing.

There are five steps to derive the PWV from GPS observations and details can be found in Suparta et al. (2008) and Suparta (2012). First, the total tropospheric delay is estimated by constraining the positions of widely-spaced GPS receivers and measuring the apparent error in position every 30s. When all systems related errors are accounted, the residual error is presumed to come only from the neutral atmosphere. Second, the total signal delays measured by the GPS receiver from all satellites in view map to the zenith direction using Vienna Mapping Function (VMF1) and combined to give the Zenith Total Delay (ZTD). In addition to the precise ZTD estimation accuracy, the residual tropospheric delay was minimized by implementing a single differencing technique in the pre-processing with baseline length at below $10 \mathrm{~km}$. On the other hand, the ZTD in this study is calculated based on the Modified Hopfield model. Third, the Zenith Hydrostatic Delay (ZHD) is calculated using the Saastamoinen model (Saastamoinen, 1972). This model uses the surface pressure measurement and a correction factor that corrects the gravitational acceleration at the center of mass of atmospheric column. In this study, ZHD is used to correct the errors caused by atmospheric delays on the GPS signals on the Earth's surface. Fourth, the Zenith Wet Delay (ZWD) is obtained by subtracting the ZHD from ZTD. Finally, PWV is derived from ZWD signals and a conversion factor that proportional to the weighted mean surface temperature. The mean air temperature is currently estimated from the surface temperature measured at the site. In this study, the Tropospheric Water Vapor Program (TroWav) written in Matlab (Suparta, 2010) was used to process and analyze the above parameters. For this study, the actual PWV data (in $\mathrm{kg} / \mathrm{m}^{2}$ or millimeter) at SBA has been calculated at a 10-min interval. The ZTD had an accuracy of about $1.0 \sim 1.20$ $\mathrm{cm}$ level, which corresponds to 1 2 $\mathrm{mm}$ in PWV accuracies (Suparta et al., 2008; Suparta, 2010).

To observe the annual oscillation of coreless winter properties for both regions, the GPS PWV results at THU2, SBA, REYK and SYOG were calculated following the interval in the meteorological data. The surface meteorological and PWV variations are then analyzed in daily basis in order to observe their annual pattern respective in both regions. Further, all parameters together with solar radiation data were analyzed on a monthly basis to get a clearly observed pattern of coreless winter behavior.

\section{RESULTS}

Daily variations: Figure 2 shows the daily variations of surface parameters from 1 January until 31 December of 2009 in the Antarctic and Arctic, respectively. On the left of Fig. 2a presents the surface pressure for the SBA and SYOG that vary from 949-1025 mbar. At each station, their mean values recorded around 991 and 985 mbar, respectively. The standard deviation values at each station were about 9.3 and 9.8 mbar, respectively. For THU2 and REYK, their mean values were at 1009 and 999 mbar, respectively. However, their standard deviation values have a difference of about $3.43 \mathrm{mbar}$, which standard deviation at REYK was higher compared to THU2. The lowest and highest pressures for Arctic were recorded at the end of January and the middle of December with average values of 969 mbar and 1036 mbar, respectively. The surface pressure variations in both regions exhibited highly irregular variations as shown in the Fig. 2a. The middle panel of Fig. 2 presents the surface temperature variations at each station with average values for Antarctic ranging from-45.2-1.3 ${ }^{\circ} \mathrm{C}$. Mean values for SBA and SYOG were about-19.5 and$10.4^{\circ} \mathrm{C}$, respectively. The range temperature for REYK varies between -7.2 and $15.5^{\circ} \mathrm{C}$ with a mean value of about $5.5^{\circ} \mathrm{C}$. At THU2, it was varied from$32.5-10.6^{\circ} \mathrm{C}\left(-8.7^{\circ} \mathrm{C}\right.$, on average) with an extreme minimum value was recorded at $-34.2^{\circ} \mathrm{C}$ in March. 


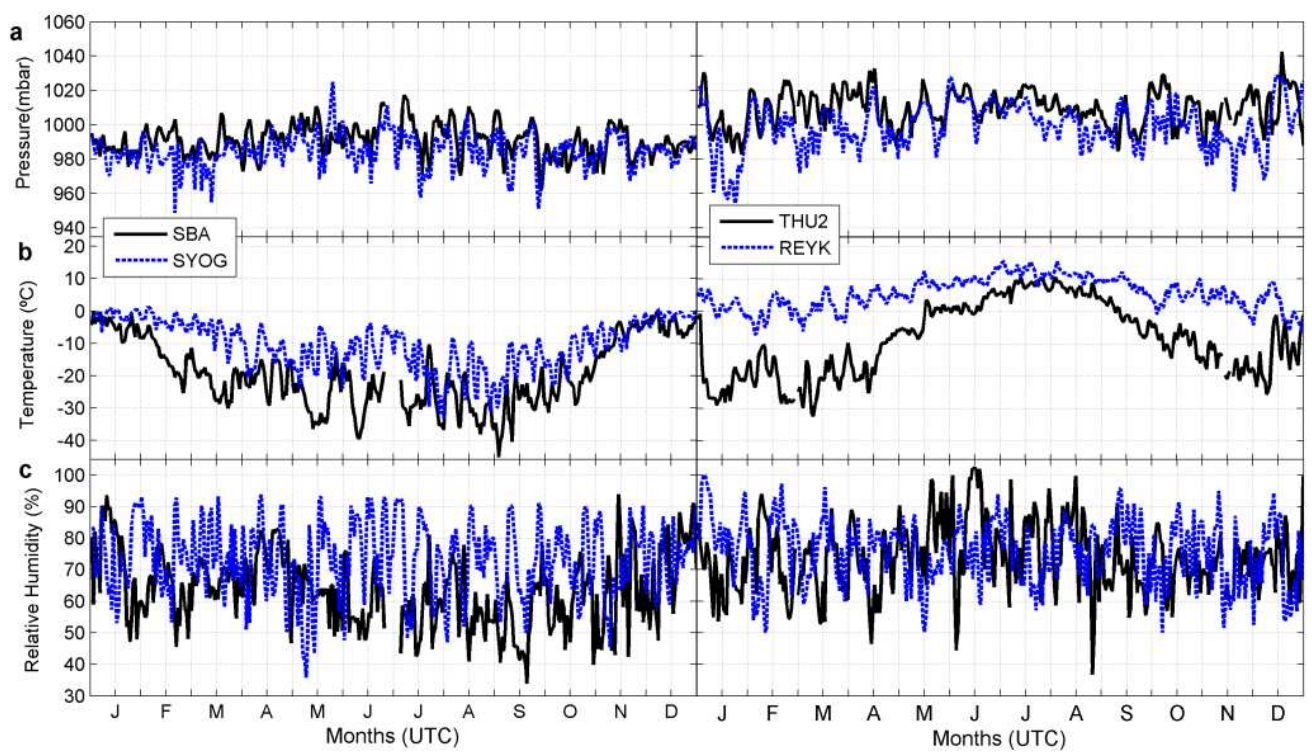

Fig. 2: Daily average of the surface meteorology variations for the year of 2009 at two stations in bipolar region. The month label in the figure represents the middle of the month in UTC

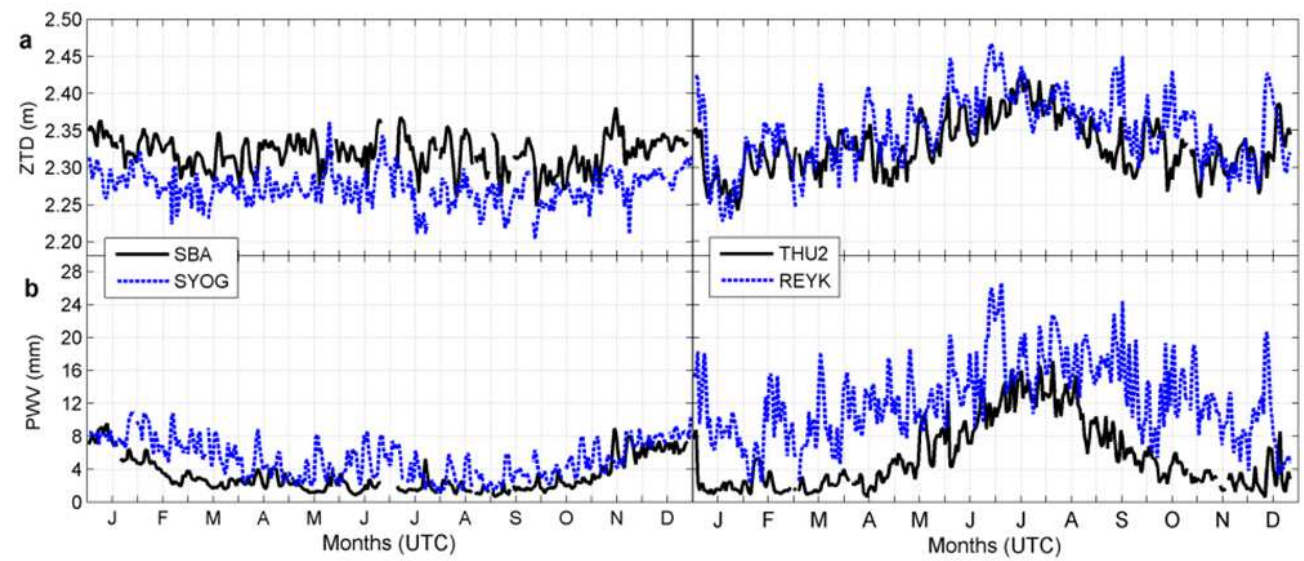

Fig. 3: Daily average of PWV and ZTD variations for the year of 2009 at two stations in bipolar region

SBA and THU2 have high standard deviation values compared to SYOG and REYK with differences of 2.8 and $6.5^{\circ} \mathrm{C}$, respectively. From recorded temperature, Arctic demonstrates a large amount of heat compared to Antarctic temperature with difference mean value about $13.3^{\circ} \mathrm{C}$. The bottom panel of Fig. 2 presents the variations of relative humidity for SBA and SYOG with mean values were about 63 and $73 \%$, respectively and for THU2 and REYK are 74 and $75 \%$, respectively. The standard deviation values for SBA and SYOG are very close to about $12 \%$, while for THU2 and REYK had a difference of about $1 \%$. The relative humidity at REYK shown a small fluctuation compared to THU2, whereas the humidity at THU2 demonstrated increases from May to August and started decreasing in September.

Figure 3 presents a daily average of GPS parameters such as ZTD and PWV variations in year of 2009 for Antarctic and Arctic, respectively. As shown in the left panel of Fig. 3a, the ZTD for Antarctic varies from 2.20 to $2.38 \mathrm{~m}$ with mean values of each station are $2.32 \mathrm{~m}$ (SBA) and $2.27 \mathrm{~m}$ (SYOG). On the other hand, ZTD for Arctic varies from 2.23-2.47 m (2.34 m, on average). Average of standard deviation values for Antarctic is smaller than in the Arctic with a difference about $0.02 \mathrm{~m}$. However, daily variations of ZTD in both regions showed a similar trend with the surface temperature pattern of each region as shown in Fig. $2 b$. 


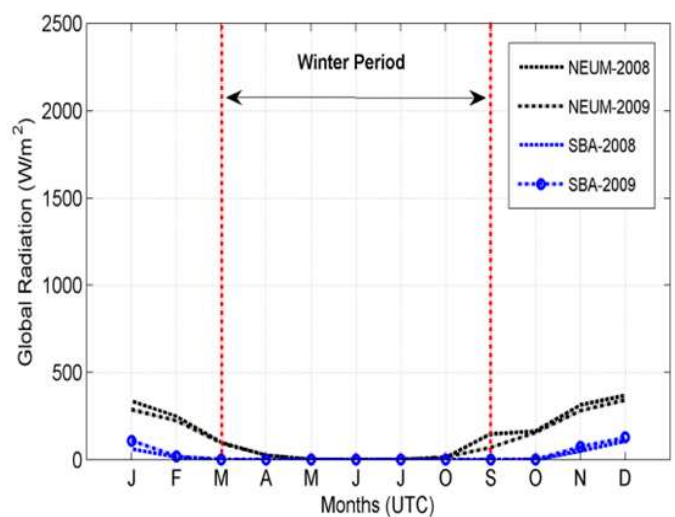

(a)

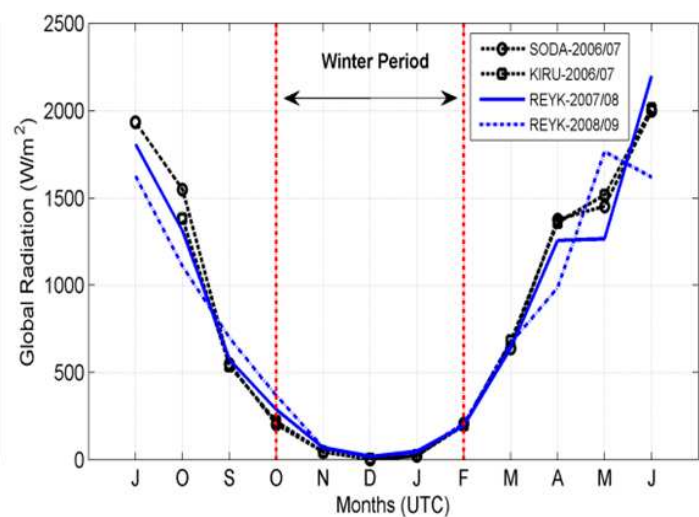

(b)

Fig. 4: Monthly average of global solar radiation in bipolar region from January 2008 to December 2009 and from July 2007 to June 2009 for Antarctic and Arctic, respectively

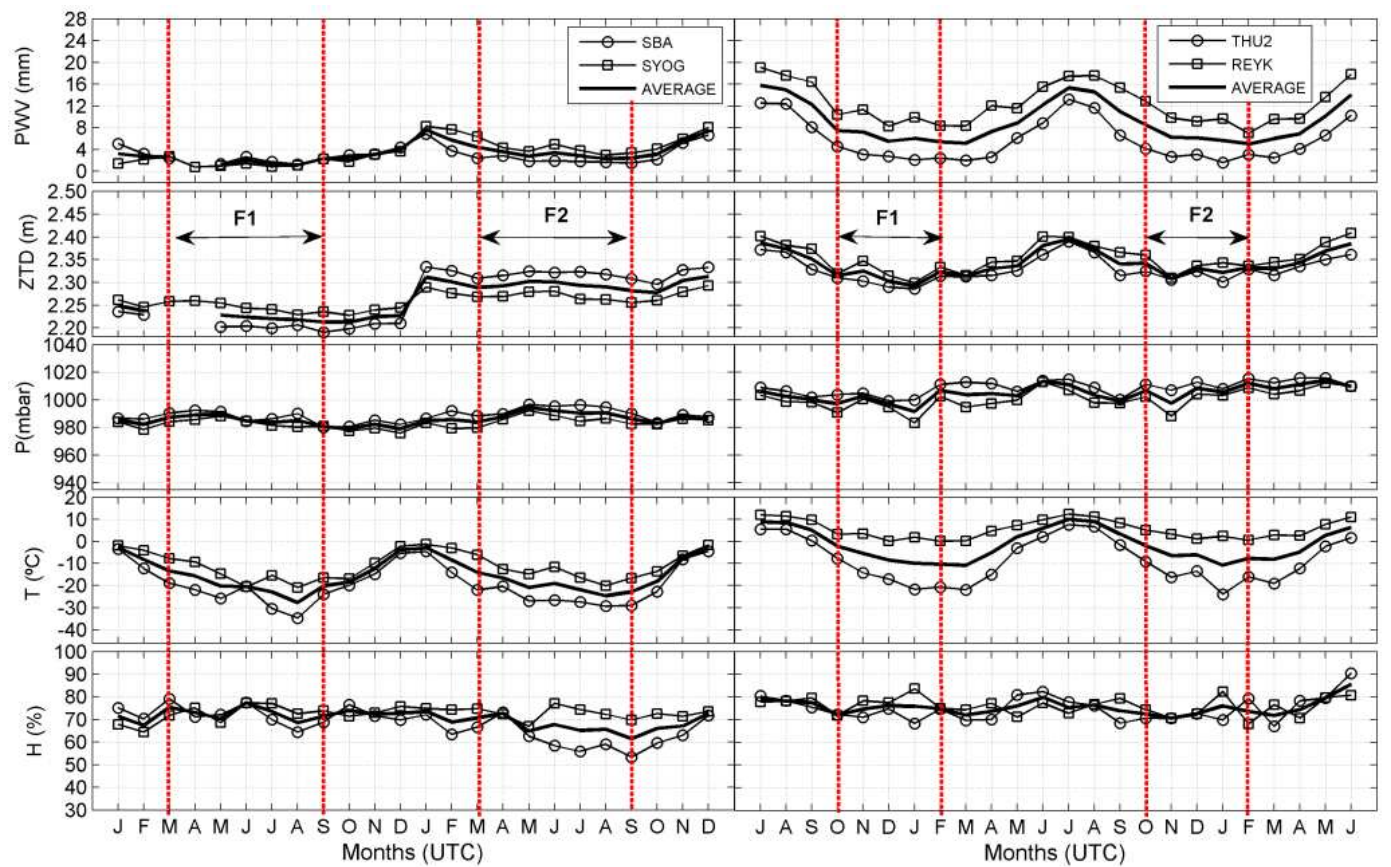

Fig. 5: Monthly average of GPS and the surface meteorology parameters for the year of January 2008 to December 2009 (Antarctic) and from July 2008 to June 2010 (Arctic)

In addition, the daily pattern of PWV in both regions also showed U-distribution as alike with the temperature and ZTD pattern as shown in the Fig. $3 b$. Therefore, the annual of PWV variations in the bipolar region showed lower variation in Austral winter and higher variation in Austral summer. As shown on the left of Fig. 3b, the mean values of PWV measurements observed in Antarctic ranging from 0.65-11.02 mm, with mean values are 3.23 and $5.28 \mathrm{~mm}$ for SBA and SYOG, respectively. While for Arctic, the average
PWV values varied from $0.60-26.70 \mathrm{~mm}$, with mean values are 5.55 and $12.40 \mathrm{~mm}$ for THU2 and REYK, respectively. The PWV at REYK shown highly variation compared to the PWV at THU2. This high fluctuation is possibly due to its location that tendency had stormy weather influenced by the battle of the Irminger Current and East Greenland Current (Nowotarski et al., 2006). In this study, it is noted that the PWV value in the Arctic was observed approximately twice larger compared to the PWV at Antarctic. 
Solar radiation pattern: Figure 4 shows the monthly mean variation of global solar radiation component in both regions, which is represented by SBA and NEUM for Antarctic and REYK, SODA and KIRU are signified for the Arctic. In the figure, because of lack availability of recent data at high latitudes above the Arctic Circle, solar data at SODA and KIRU for the period from July 2006 to June 2007 was chosen to compare data at REYK. The monthly mean difference between REYK with SODA and KIRU are 46.24 and $59.96 \mathrm{~W} / \mathrm{m}^{2}$, respectively. On the other hand, the monthly mean of global radiation for year 2008 and 2009 at SBA and NEUM are $23.75 \mathrm{~W} / \mathrm{m}^{2}$ and 133.96 $\mathrm{W} / \mathrm{m}^{2}$, respectively, with an average difference between the two stations is about $110.21 \mathrm{~W} / \mathrm{m}^{2}$. As shown in Fig. 4, total annual of solar radiation penetrates higher in the Arctic compared to the Antarctic, with an average of the global component in the Arctic was larger about 10 times than in the Antarctic.

The low solar radiation variations recorded at both stations in each region are employed to represent the winter period in Antarctic and Arctic, respectively. In addition, the Earth receives a total amount of radiation in one cross-area is about one-fourth of the solar constant $\left(342 \mathrm{~W} / \mathrm{m}^{2}\right)$. Therefore, the occurrence of winter period can be assumed for both regions are lower than the one-fourth of the solar constant. On the right of Fig. 4 showed that SBA received low solar radiation around nine consecutive months since February (polar sunset) to October (polar morning) with nearly about zero values. Meanwhile, NEUM received only around six months of low solar radiation from March until September. As a result, the defined winter period in Antarctic according to the solar pattern agreed from both stations were between March and September. On the other hand, the winter period in the Arctic was defined from solar radiation at both stations that are recorded low about five months which from October to February. For seasonal variations in Antarctica, SBA and NEUM showed maximum during summer (polar day) and the minimum in winter (polar night). In contrast with solar radiations at REYK and SODA, it nearly followed the Austral Northern Hemisphere seasons, which had shown increasing in spring and maximum in summer, whereas in autumn, the variations were declining. The average difference during the winter period and summer period in 2008 and 2009 for Antarctic is $175.11 \mathrm{~W} / \mathrm{m}^{2}$. While for Arctic, the average differences between the winter period and the austral seasons of summer, autumn and spring between both stations are about 1621.04, 475.39 and $1020.18 \mathrm{~W} / \mathrm{m}^{2}$, respectively. In addition, the definition by winter periods for both regions as shown in Fig. 4, are applied in order to use to analyze the characteristics of expected coreless winter in both regions.
Characteristic of coreless winter: In general, the significant unusual warm temperature peaks noticeably occurred during winter was identified as a coreless winter event (Kodama and Wendler, 1985). In line of this event, the monthly mean of GPS parameters and surface meteorology profiles at four stations are presented in order to observe the behavior of coreless winter in both regions (Fig. 5). To observe clearly the characteristics of coreless winter, the analyses have been focused during the defined period of winter for two years as indicated by two events as F1 and F2. For the Antarctic, both events, F1 and F2 were from March to September of 2008 and March to September of 2009, respectively. Meanwhile in the Arctic, F1 was from October 2008 to February 2009 and F2 from October 2009 to February 2010.

Observation the impact of coreless winter in bipolar regions to the GPS can be seen through a monthly mean of PWV and ZTD as shown in the first and second panel of Fig. 5. In the first event (F1) for Antarctic region, PWV for each station showed low variations in the winter period and then increasing in September. However, variations of PWV peaked in June for SBA and in May and June for SYOG increased for each station of about $1.28 \mathrm{~mm}$ and $0.31 \mathrm{~mm}$, respectively. At the same time, ZTD had shown high variation in SYOG from March to May while low variation in SBA but still demonstrated peaked in August. Meanwhile for the Arctic, PWV had shown a peak during the winter period clearly in REYK which occurred in November and January, while THU only showed in February. The average of PWV peaks for each station about $1.31 \mathrm{~mm}$ and $0.30 \mathrm{~mm}$, respectively. Moreover, the increase peaks of PWV in Arctic are related to the ZTD peaks which occurred at same months. During the F2 event, the PWV at both stations in Antarctic showed low variations same as in the F1. In addition, there is PWV peaked in April and June for SBA and June in SYOG with the average increasing for both stations about $2.73 \mathrm{~mm}$. ZTD in the F2 depicted similar variations at both stations, which increase from March to June. However, the high variation in SBA continued until in July and decrease in October, while SYOG showed decreased from July until September. Furthermore, ZTD in 2009 also showed higher variation than in 2008. In the F2 event for the Arctic, the PWV showed a peak in January for REYK and in December and February for THU2. qVariations of ZTD in the F2 showed a peak in December and January for REYK and in December and February for THU2 with an average of peak at each station were about 2.34 $\mathrm{m}$ and $2.33 \mathrm{~mm}$, respectively. 
To correlate the impacts of coreless winter on other parameters, monthly mean of surface meteorology variation was compared as shown in the third to the fifth panel of Fig. 5. In the F1, the surface pressure variations in the Antarctic had shown gradually increased from March to May and then decreased from June until September. However, pressure in SBA showed increase peak in August at 990 mbar. On the other hand, pressure in Arctic showed decreasing from beginning month until January and then increased in February. Although pressure in THU2 demonstrated increasing peak at 1005 mbar in November. For the surface temperature profiles, their trends during winter period are closely at PWV trend. As alike in PWV, the temperature trends in both regions had shown decreased during the winter period and later they increased back in September for Antarctic and in February for Arctic. This increasing trend was signifying the transition of winter to summer season. However, there were few warming peaks occurred during $\mathrm{F} 1$ events which in June at SBA and in July at SYOG while in November and January at REYK. In contrast, THU2 not showed any increase peak at this event. Increasing temperatures in the F1 for SBA, SYOG and REYK are about 5.5, 5.2 and $0.9^{\circ} \mathrm{C}$, respectively. Afterward, relative humidity in Antarctic showed sinusoidal variations, which started decreasing from March to May then, increased in June after that decreased from July to August and increased again in September. Increasing peak of relative humidity in June during the F1 at SBA and SYOG are about 5.4 and $8.8 \%$, respectively. Meanwhile, relative humidity in Arctic showed irregular variations at both stations, which increasing peaks occurred in November and January for REYK and in December for THU2 with the average increasing for each station about 6.3 and $5 \%$, respectively.

In the second year of the event (F2), the surface pressure in Antarctic showed a similar pattern as in the F1, which gradually increased from beginning until in the middle of winter and followed by decreased at the end of the winter period. The decreasing of surface pressure was possibly due to the depressions of circumpolar vortex. However, pressure in the Arctic for F2 had shown an opposite pattern as in the F1, which pressure decreased in November and then increased back until after February. Afterward, temperature variations in the F2 at both regions showed a close pattern as in the F1. However, both regions showed warm peaks occurred in the F2, which in April and June for Antarctic and in December and January for Arctic. The average increases of warm peak for each region are about 1.7 and $2.0^{\circ} \mathrm{C}$, respectively. For relative humidity at both regions showed an irregular pattern in the F2. For the Antarctic, relative humidity demonstrated a decrease trend, although there are increasing peak occurred in June at SYOG and in August at SBA. In contrast, the humidity in Arctic exhibited an increase trend during F2 with significant peak of $82 \%$ showed in January for REYK.

\section{DISCUSSION}

According to the Fig. 5, coreless winter phenomenon of two-year observations found majority occurred in June and December for Antarctic and Arctic, respectively. All parameters have a similar characteristic, which they showed an increasing trend (warm peak) during the winter period. However, the coreless winter occurrences in each station are arising at a different time (month). The average frequency incidents of warming in every year for all parameters at each station are summarized in Table 2 .

Based on Table 2, the frequent incidents of warm peaks during winter period are differences in all parameters. This occurrence may due to dissimilarity in the environment and position (topography) that affect the weather or conditions at each station. Even though, they were located near to the coastal areas, but they might have experienced with a distinct effect because they were linked with a different of the ocean. For example, in the Antarctic, SBA connected to the South Pacific Ocean and SYOG linked to the Indian Ocean and Atlantic Ocean. Meanwhile for the Arctic, REYK positioned nearly in a pathway of North Atlantic Current, which causes climate of this island more temperate than other places in the Arctic region. THU2 is affected by the Arctic Ocean. On the other hand, each part has different climatic characteristics and sea-ice physical properties (Brandt et al., 2005; Ozsoy-Cicek et al., 2011). Corresponding to Table 2, the coreless winter phenomenon was significant occurred in Antarctic compared to the Arctic with a frequency of warming episodes is higher. Moreover, based on the differences between the maximum warm peak and average values during the winter period in each year noted that these events more pronounced in the Antarctic than in the Arctic. Almost parameters at each station in Antarctic showed higher values than the average values. Meanwhile, the warm peak at Arctic was observed more prominent in REYK for two years observation, while THU2 only took place in 2009/2010. This may due to THU2 was corresponded too much of Arctic climate in which during winter, the cold snow cover has been reflected the solar radiation between 70 and $90 \%$ that reaches the surface (Serreze and Barry, 2005). Therefore, the cold rate was higher than the rate of warming of coreless winter. 
Am. J. Applied Sci., 9 (8): 1203-1213, 2012

Table 2: Statistic analysis of GPS and the surface meteorology parameters during coreless winter in bipolar regions

\begin{tabular}{|c|c|c|c|c|}
\hline Parameter & Station & $\begin{array}{l}\text { Frequency } \\
\text { CW/year }\end{array}$ & $\begin{array}{l}\Delta \mathrm{T} 1 \\
(\mathrm{An}-2008, \\
\text { Ar-2008/09) }\end{array}$ & $\begin{array}{l}\Delta \mathrm{T} 2 \\
(\mathrm{An}-2009, \\
\text { Ar-2009/10) }\end{array}$ \\
\hline \multirow[t]{4}{*}{$\overline{P W V}(\mathrm{~mm})$} & SBA & 1 & 0.720 & 0.830 \\
\hline & SYOG & 1 & -0.140 & 0.770 \\
\hline & REYK & 2 & 1.690 & -0.050 \\
\hline & THU2 & 1 & - & 0.190 \\
\hline ZTD & SBA & 2 & 0.007 & 0.008 \\
\hline \multirow[t]{3}{*}{$(\mathrm{m})$} & SYOG & 2 & 0.014 & 0.010 \\
\hline & REYK & 2 & 0.028 & 0.010 \\
\hline & THU2 & 2 & 0.009 & 0.015 \\
\hline $\mathrm{P}$ & SBA & 3 & 4.780 & 3.470 \\
\hline \multirow[t]{3}{*}{ (mbar) } & SYOG & 3 & 4.700 & 6.400 \\
\hline & REYK & 1 & 6.700 & 2.800 \\
\hline & THU2 & 1 & 1.300 & 2.200 \\
\hline $\mathrm{T}$ & SBA & 1 & 4.710 & 5.550 \\
\hline \multirow[t]{3}{*}{$\left({ }^{\circ} \mathrm{C}\right)$} & SYOG & 2 & 0.060 & 2.420 \\
\hline & REYK & 1 & 1.660 & -0.140 \\
\hline & THU2 & 1 & - & 8.960 \\
\hline & SBA & 2 & 5.360 & 11.920 \\
\hline \multirow[t]{3}{*}{$(\%)$} & SYOG & 2 & 3.540 & 4.590 \\
\hline & REYK & 2 & 6.360 & 8.730 \\
\hline & THU2 & 1 & 2.190 & -0.010 \\
\hline
\end{tabular}

Note: $\Delta \mathrm{T}=$ Maximum of warming peak-average parameter during winter. $(\mathrm{An}=$ Antarctic, $\mathrm{Ar}=$ Arctic $)$

Overall, the coreless winter phenomenon for this location may due to the warm air advections of difference temperature between the sea ice cover and sea surface temperature (Styszynska, 2004). The sea ice extent regulates an exchange of heat, which the circulation occurred when it insulates the relatively warm air from ocean water flows over the cool air on the ice surface. Consequently, the heat exchange will occur and increase the air temperature. The large difference between sea surface temperature and ice cover also promoting the existence of storm activity in the polar winter as reported by Predoehl and Spano (1965). In addition, the heat exchanges of sea ice will permit water vapor to transport from the ocean to the atmosphere. Hence, the water vapor transportation to the atmosphere may affect and could be a delay in the GPS signals, particularly in the tropospheric delay.

\section{CONCLUSION}

The study constitutes a significant contribution regarding the applications of GPS meteorology for coreless winter detection. The use of GPS derived Precipitable Water Vapor (PWV) to detect and to characterize a specific climate event such as coreless winter is innovator in particular for the targeted region. In this study, the characterization of coreless winter and their effect on the GPS PWV variability within the Antarctic and Arctic regions have been successfully addressed. The observations carried out two years during the winter period showed that June and January months was identified as the month of coreless winter events for Antarctic and Arctic, respectively. During the period of winter in both regions, variation of PWV, ZTD, the temperature and relative humidity demonstrated directly proportional to each other than with the surface pressure. These four parameters had large impacts in the slight warming of the atmosphere in the middle of winter. During these coreless winter events, roughly, an increasing in $1^{\circ} \mathrm{C}$ of the temperature will increase the PWV content of about $0.21 \mathrm{~mm}$ and $0.46 \mathrm{~mm}$ for Antarctic and Arctic, respectively. In other words, the PWV value at Arctic has been quantified at approximately twice larger compared to the Antarctic. This clarifies that the warming amplification in the Arctic is faster than with the Antarctic.

From the GPS Meteorology observations, the coreless winter was signifying when the significant warm in temperature related to the warm air advections to the difference temperature between the sea ice cover and sea surface temperature. The circulation will occur when the warmest water surface flows over the cool air surface; hence, the heat exchange will increase the air temperature and water vapor. As well, the increasing of temperature and PWV might be affected by the increasing of mixing warm or cold air mass advection from the strong wind speeds that will intensify cyclone activity and the traveling cyclones that will bring the precipitations.

The analysis can be concluded that the increasing of PWV during winter in both regions, suggests that the GPS signals had slightly delayed that would be problems in the positioning application. Although a small increase of PWV during winter because of no or low solar radiation received in that region, its phase would be very significant in order to enhance the capability of ground-based GPS as a remote sensing tool to monitor the atmospheric water vapor, as well as their capability of detecting the coreless winter effect. The PWV variability was closely following the temperature patterns, indicating the evidence of a seasonal signal in both regions; highest in summer and lowest in winter and the unusual warming in the middle of winter. The characterization of the response of surface meteorology and PWV parameters during winter showed that PWV data has more capabilities and consistent in detecting the period of coreless winter, instead of conventional assessment method from the inversion of surface air temperature. However, the prospective PWV data for climate studies was not complementing to traditional measurements. Although the time occurrence of coreless winter at any region differs due to the influence of air circulation factors, the high temporal and continuous GPS PWV data presented here has a great potential 
to monitor the characteristics of the atmosphere, in particular in sensitive areas at the poles.

\section{ACKNOWLEDGEMENT}

This study was supported by the Ministry of Higher Education Malaysia (MOHE) under grant UKM-LL-07-FRGS0211-2010. The authors thank the managerial staff and science technicians of Antarctica New Zealand (ANZ) for their full support and kind hospitality at Scott Base and Andrew R. Harper at the National Institute of Water and Atmospheric Research Ltd., New Zealand (NIWA) for supporting the surface meteorological data. Thanks to the World Radiation Data Center (WRDC) and Alfred Wegner Institute (AWI) for supporting solar radiation data. The authors are also grateful to SOPAC for their archives of GPS and meteorology data and the British Antarctic Survey (BAS) for their meteorology data archives. Finally, the authors like to thank the Malaysian Antarctic Research Program (MARP) and Academy Science of Malaysia through the Ministry of Science, Technology and Innovation (MOSTI) Malaysia for supporting this research under the PKT1/2003 grant.

\section{REFERENCES}

Anisimov, O.A., D.G. Vaughan, T.V. Callaghan, C. Furgal and H. Marchant, et al., 2007. Polar Regions (Arctic and Antarctic). In: Climate Change 2007: Impacts, Adaptation and Vulnerability: Contribution of Working Group II to the Fourth Assessment Report of the Intergovernmental Panel on Climate Change, Parry, M.L., (Ed.). Cambridge University Press, Cambridge, ISBN-10: 0521880106, pp: 653- 685.

Bevis, M., S. Businger, T.A. Herring, C. Rocken and R.A. Anthes et al., 1992. GPS Meteorology: Remote sensing of atmospheric water vapor using the Global Positioning System, J. Geophys. Res., 97: 15787-15801. DOI: 10.1029/92JD01517

Brandt, R.E., S.G. Warren, A.P. Worby and T.C. Grenfell, 2005. Surface albedo of the Antarctic sea ice zone, J. Climate, 18: 3606-3622. DOI: 10.1175/JCLI3489.1

Carroll, J.J., 1982. Long-term means and short-term variability of the surface energy balance components at the South Pole, J. Geophys. Res., 87: 4277-4286. DOI:10.1029/JC087iC06p04277

Connolley, W.M. and H. Cattle, 1994. The Antarctic climate of the UKMO Unified Model, Antarctic Sci., 6: 115-122. DOI: $10.1017 /$ S0954102094000143
Duan, J., M. Bevis, P. Fang, Y. Bock and S. Chiswell et al., 1996. GPS meteorology: Direct estimation of the absolute value of precipitable water, J. Appl. Meteor., 35: 830-838. DOI: 10.1175/15200450(1996)035<0830:GMDEOT>2.0.CO;2

Elgered, G., J.M. Johansson, B.O. Ronnang and J.L. Davis, 1997. Measuring regional atmospheric water vapor using the Swedish permanent GPS network, Geophys. Res. Lett., 24: 2663-2666. DOI: 10.1029/97GL02798

Gradinasky, L.P., J.M. Johansson, H.R. Bouma, H.G. Scherneck and G. Elgered, 2002. Climate monitoring using GPS, J. Phys. Chem. Earth, Parts $\mathrm{A} / \mathrm{B} / \mathrm{C}, \quad 27: \quad 335-340$. DOI: $10.1016 / \mathrm{S} 1474-$ 7065(02)00009-8

Gutman, S.I., R.B. Chadwick, D.W. Wolfe, A. Simon, T.V. Hove et al., 1994. Toward an operational water vapor remote sensing system using the global positioning system.

Haan, S.D., 2008. Meteorological applications of a surface network of global positioning system receivers. Ph.D Thesis, Wageningen University, Wageningen.

Hudson, S.R. and R.E. Brandt, 2005. A look at the surface-based temperature inversion on the Antarctic Plateau, J. Clim., 18: 1673- 1696. DOI: 10.1175/JCLI3360.1

King, J.C. and S.A. Harangozo, 1998. Climate change in the western Antarctic Peninsula since 1945: Observations and possible causes, J. Ann. Glaciol., 27: 571-575.

Kodama, Y. and G. Wendler, 1984. Coreless winter in Adelie Land. University of Alaska.

Kuo, Y.H., S. Sokolovskiy, R.A. Anthes and F. Vandenberghe, 2000. Assimilation of GPS radio occultation data for Numerical Weather Prediction, Special issue of Terr. Atmos. Ocean Sci., 11: 157-186.

McBean, G., , 2005. Arctic Climate: Past and Present. In: Symon, Arctic Climate Impacts Assessment ACIA, (Ed.). Cambridge University Press, Cambridge, United Kingdom, ISBN-10: 0521865093, pp: 21-60.

Nowotarski, C., M. Popek, A. Matus and A. Kourakos, 2006. Climate analysis and observations for Reykjavik, Iceland.

Ozsoy-Cicek, B., S.F. Ackley, A.P. Worby, H. Xie and J.L. Lieser, 2011. Antarctic sea-ice extents and concentrations: comparison of satellite and ship measurements from International Polar Year cruises, J. Ann. Glaciol., 52: 318-326. DOI: $10.3189 / 172756411795931877$ 
Predoehl, M.C. and A.F. Spano, 1965. Airborne albedo measurements over the Ross Sea, OctoberNovember 1962, Mon. Wea. Rev., 93: 687-696. DOI: $10.1175 / 1520$ 0493(1965)093<0687:AAMOTR>2.3.CO;2

Rocken, C., T.V. Hove and R. Ware, 1997. Near realtime GPS sensing of atmospheric water vapor. Geophys. Res. Lett., 24: 3221-3224. DOI: 10.1029/97GL03312

Saastamoinen, J., 1972. Introduction to practical computation of astronomical refraction, Bull. Geod., 46: 383-397. DOI: 10.1007/BF02522047

Serreze, M.C. and J.A. Francis, 2006. The Arctic amplification debate, J. Climatic Change, 76: 241264. DOI: $10.1007 / \mathrm{s} 10584-005-9017-y$

Serreze, M.C. and R.G. Barry, 2005. The Arctic Climate System. 1st Edn., Cambridge University Press, New York, ISBN-10: 9780521814188. pp: 385 .

Stone, R.S. and J.D. Kahl, 1991. Variations in boundary layer properties associated with clouds and transient weather disturbances at the South Pole during winter, J. Geophys. Res., 96: 5137-5144. DOI: 10.1029/90JD02605

Styszynska, A., 2004. The origin of coreless winter in the South Shetlands area (Antarctica), J. Polish Polar Res., 25: 45-66.
Suparta, W., Z.A.A. Rashid, M.A. Mohd Ali, B. Yatim and G.J. Fraser, 2008. Observations of Antarctic precipitable water vapor and its response to the solar activity based on GPS sensing, J. Atmos. SolTerr. Phys., 70: 1419-1447. DOI: 10.1016/j.jastp.2008.04.006

Suparta, W., 2010. Using a Global Positioning system to estimate precipitable water vapor in Antarctica, Polar Geog., 33: 63-79. DOI: 10.1080/1088937X.2010.498683

Suparta, W., 2012. Detection of a katabatic wind event with GPS meteorology measurements at Scott Base Antarctica, Meteorol. Atmos. Phys., 115: 153-162.

Turner, J., J.E. Overland and J.E. Walsh, 2007. An Arctic and Antarctic perspective on recent climate change, Int. J. Climatol., 27: 277-293. DOI: 10.1002/joc.1406

Bromwich, D.H. and C.R. Stearns, 1993. Antarctic meteorology and climatology: Studies based on automatic weather stations, antarct. Res. Ser., 61: 207-207. DOI: 10.1029/AR061

Wexler, H., 1958. The "kernlose" winter in Antarctica. Geophysics, 6: 577-595. 